\title{
Author Correction: Integrated molecular subtyping defines a curable oligometastatic state in colorectal liver metastasis
}

Sean P. Pitroda ${ }^{1,2}$, Nikolai N. Khodarev1,2, Lei Huang ${ }^{3}$, Abhineet Uppal ${ }^{4}$, Sean C. Wightman ${ }^{4}$, Sabha Ganai ${ }^{5}$, Nora Joseph ${ }^{6}$, Jason Pitt ${ }^{7}$, Miguel Brown ${ }^{7}$, Martin Forde ${ }^{7}$, Kathy Mangold (1) ${ }^{6}$, Lai Xue ${ }^{4}$, Christopher Weber ${ }^{8}$, Jeremy P. Segal ${ }^{8}$, Sabah Kadri ${ }^{8}$, Melinda E. Stack ${ }^{4}$, Sajid Khan ${ }^{9}$, Philip Paty ${ }^{10}$, Karen Kaul ${ }^{6}$, Jorge Andrade ${ }^{3}$, Kevin P. White 7,11 , Mark Talamonti ${ }^{12}$, Mitchell C. Posner ${ }^{4}$, Samuel Hellman ${ }^{1,2} \&$ Ralph R. Weichselbaum ${ }^{1,2}$

Correction to: Nature Communications; https://doi.org/10.1038/s41467-018-04278-6, published online 04 May 2018.

In the originally published version of this Article, the affiliation details for Kevin P. White inadvertently omitted 'Tempus Labs, Chicago, IL, 60654, USA'. This has now been corrected in both the PDF and HTML versions of the Article.

Published online: 13 November 2018

Open Access This article is licensed under a Creative Commons Attribution 4.0 International License, which permits use, sharing, adaptation, distribution and reproduction in any medium or format, as long as you give appropriate credit to the original author(s) and the source, provide a link to the Creative Commons license, and indicate if changes were made. The images or other third party material in this article are included in the article's Creative Commons license, unless indicated otherwise in a credit line to the material. If material is not included in the article's Creative Commons license and your intended use is not permitted by statutory regulation or exceeds the permitted use, you will need to obtain permission directly from the copyright holder. To view a copy of this license, visit http://creativecommons.org/licenses/by/4.0/.
\end{abstract}

(C) The Author(s) 2018

\footnotetext{
${ }^{1}$ Department of Radiation and Cellular Oncology, The University of Chicago, Chicago, IL 60637, USA. ${ }^{2}$ Ludwig Center for Metastasis Research, The University of Chicago, Chicago, IL 60637, USA. ${ }^{3}$ Center for Research Informatics, The University of Chicago, Chicago, IL 60637, USA. ${ }^{4}$ Department of Surgery, The University of Chicago, Chicago, IL 60637, USA. ${ }^{5}$ Department of Surgery, Southern Illinois University, Springfield, IL 62702, USA. ${ }^{6}$ Department of Pathology, NorthShore University Hospital, Evanston, IL 60201, USA. ${ }^{7}$ Institute for Genomics and Systems Biology, The University of Chicago, Chicago, IL 60637, USA. ${ }^{8}$ Department of Pathology, The University of Chicago, Chicago, IL 60637, USA. ${ }^{9}$ Department of Surgery, Yale School of Medicine, New Haven, CT 06510, USA. ${ }^{10}$ Department of Surgery, Memorial Sloan-Kettering Cancer Center, New York, NY 10065, USA. ${ }^{11}$ Tempus Labs, Chicago, IL 60654, USA. 12 Department of Surgery, NorthShore University Hospital, Evanston, IL 60201, USA. Correspondence and requests for materials should be addressed to R.R.W. (email: rrw@radonc.uchicago.edu)
} 